Article

\title{
Pandemic Populism? How Covid-19 Triggered Populist Facebook User Comments in Germany and Austria
}

\author{
Daniel Thiele \\ Department of Political Science, University of Vienna, Austria; daniel.thiele@univie.ac.at
}

Submitted: 16 July 2021 | Accepted: 15 October 2021 | Published: 17 February 2022

\begin{abstract}
Covid-19 and the government measures taken to combat the pandemic have fueled populist protests in Germany and Austria. Social media played a key role in the emergence of these protests. This study argues that the topic of Covid-19 has triggered populist user comments on Facebook pages of German and Austrian mass media. Drawing on media psychology, this article theorizes populist comments as an expression of "reactance," sparked by repeated "fear appeals" in posts about Covid-19. Several hypotheses are derived from this claim and tested on a dataset of $N=25,121$ Facebook posts, posted between January 2020 and May 2021 on nine pages of German and Austrian mass media, and 1.4 million corresponding user comments. To measure content-based variables automatically, this study develops, validates, and applies dictionaries. The study finds that the topic of Covid-19 did trigger populist user comments and that this effect grew over time. Surprisingly, neither the stringency of government measures nor mentions of elitist actors were found to have the expected amplifying effect. The study discusses the findings against the background of governing the ongoing crisis and worrisome developments in the online public sphere.
\end{abstract}

\section{Keywords}

Covid-19; fear appeals; populism; social media; user comments

Issue

This article is part of the issue "Analyzing Citizen Engagement With European Politics Through Social Media" edited by Pieter de Wilde (Norwegian University of Science and Technology), Astrid Rasch (Norwegian University of Science and Technology), and Michael Bossetta (Lund University).

(C) 2022 by the author(s); licensee Cogitatio (Lisbon, Portugal). This article is licensed under a Creative Commons Attribution 4.0 International License (CC BY).

\section{Introduction}

In the course of the Covid-19 crisis, the government measures taken to combat the pandemic have been increasingly met with protests in several European countries. In Germany and Austria, these protests by "coronasceptics" have been particularly visible as large-scale demonstrations and on social media. Initial research has linked these protests to populist ideology, highlighting that both populists and coronasceptics deeply distrust elites and reject restrictions of "the people's" will (Brubaker, 2021; Eberl et al., 2021; Nachtwey et al., 2020). Although other scholars have stressed that there is no uniform response of populists to Covid-19 (Wondreys \& Mudde, 2020), empirical studies remain scarce.

This study focuses on populist responses of ordinary citizens to Covid-19 on social media. More specifi- cally, this article analyzes how the topic of Covid-19 and aspects of the crisis management affected the scope of populist user commenting on Facebook pages of German and Austrian news media outlets. Facebook has proven to be a preferred medium of populist citizens (Schulz, 2019) and gained importance for expressing protest during lockdowns when much of public life has shifted online (Pressman \& Choi-Fitzpatrick, 2021). Boberg et al. (2020) argued that a "pandemic populism" is unfolding on Facebook. The aim of this study is to contribute to our understanding of the conditions that give rise to citizen engagement in populist grassroots politics on social media. Understanding these conditions is vital in the ongoing Covid-19 crisis because this helps to assess problems of the crisis communication and to find political strategies for countering a trend toward post-truth politics (Waisbord, 2018a). 
Populist communication research so far has been focused on communication by political elites (e.g., Blassnig \& Wirz, 2019; Ernst et al., 2019) or by the media (e.g., Wettstein et al., 2018), or on its effects (e.g., Rooduijn et al., 2017). Few studies, however, have focused on populist messages generated by regular users of online platforms (Blassnig et al., 2019; Galpin \& Trenz, 2019). None of these studies has focused on Facebook comments or researched the impact of news topics on populist user comments. This study asks how the topic of Covid-19 and certain aspects of the crisis management affected populist user comments on Facebook pages of German and Austrian mass media outlets.

Discussing the news in user comments on social media has the potential to foster public deliberation (Dahlberg, 2011). However, reality often looks different. In the "participatory populism" scenario, a small but active group of users engages in writing comments that demonize elites, undermine the institutions of representative democracy, and counter the news or expert knowledge with "common sense" (Galpin \& Trenz, 2019). This article expects that during the crisis, the topic of Covid-19 has attracted more such populist user comments than other topics. Repeated "fear appeals" (Witte, 1992) to comply with the restrictive government measures taken to fight the pandemic may have sparked populist commenting behavior as an expression of what media psychology calls "reactance" (Dillard \& Shen, 2005). Elaborating on this argument in the theory section, this study hypothesizes that this effect grew over time, increased with the stringency of Covid measures, and was amplified by mentioning elite actors.

To test these hypotheses, this study uses an original dataset of $\mathrm{N}=25,121$ Facebook posts and 1.4M corresponding user comments, collected from nine popular Facebook pages of German and Austrian mass media outlets. The data cover a time frame from January 2020 to May 2021. The dependent variable, the number of populist Facebook comments per post, and central explanatory variables are measured by automated content analyses, using and validating Gründl's (2020) populism dictionary and self-constructed dictionaries. Hypotheses are tested in negative binomial regression models. The findings show that posts about the topic of Covid-19 did attract more populist user comments and that this effect grew over time. The study did not find the hypothesized amplifying effects of government measure stringency and mentions of elite actors. The findings are discussed against the background of governing the ongoing crisis.

\section{User Comments as Participatory Populism}

Over the past decade, social media has fundamentally changed the way political news is produced, distributed, and consumed (Klinger \& Svensson, 2015). Crucially, social media has turned the audience from receivers of content into producers themselves (Klinger
\& Svensson, 2015, p. 1246). This becomes evident in the comments feature of the most popular social media platform, Facebook (Newman et al., 2020, p. 29). Most news outlets today maintain a Facebook page where they disseminate news items in posts. Facebook users can respond directly to these posts in comments. Such comments allow users to react on specific news items (Galpin \& Trenz, 2019), engage in discussions with others (Macafee, 2013), and influence others' perceptions and behavior (Zerback \& Fawzi, 2017). Unlike anonymous user comments on media websites, Facebook comments disclose the opinion expressed by users to their network of Facebook friends (Rowe, 2015, p. 542) and increase the visibility of the post (Klinger \& Svensson, 2015). This study focuses on user comments on Facebook pages of news media outlets. Here, commenting on the news on Facebook is understood as a low-effort form of citizen engagement and political participation (Knoll et al., 2018).

From a normative perspective, user comments have the potential to contribute to a plural, participatory public sphere (Galpin \& Trenz, 2019, p. 783). Deliberative democratic theory has welcomed user comments as facilitating citizens' engagement in debates that guide informed opinion formation-given the debates meet criteria, such as reciprocity, civility, or rationality (Dahlberg, 2011; Friess \& Eilders, 2015). Comments can also give marginalized voices access to the public or foster counter-publics (Dahlberg, 2011, p. 861). Although such interactive technologies raised high hopes at the turn of the millennium, scholars paint a less positive picture of the online public sphere today. Comments sections may function as "echo chambers" that reinforce previously held beliefs and aggravate polarization among the audience (e.g., Jamieson \& Cappella, 2008). Comments are also notorious for a brusque tone and incivility, rendering the deliberative quality of online discourses questionable (e.g., Coe et al., 2014). Facebook comments have been found to exhibit even lower levels of deliberative quality than comments on news websites (Rowe, 2015). Pfetsch (2018, p. 60) argued that today's online public sphere is increasingly characterized by a discordance of citizens "up to the level of plain populism." Populist user comments on Facebook and the conditions that give rise to them are the focus of this study.

According to Mudde (2004, p. 543), populism is an ideology that clings to the idea that a "corrupt elite" rules and deceives "the people," and favors the unrestricted sovereignty of the people. At its core, populism entails the dimensions anti-elitism, people-centrism, and popular sovereignty (e.g., Ernst et al., 2019, p. 3). This ideology can manifest itself in messages from politicians and citizens alike (de Vreese et al., 2018, p. 427). Theorists have noted the ambivalent relationship between populism and democracy (e.g., Canovan, 1999; Mudde \& Kaltwasser, 2012). Although populism's demand for popular sovereignty supports a core feature of democracy, its crude majoritarianism and anti-pluralism brings it into 
conflict with liberal democracy (Canovan, 1999, p. 7; Mudde \& Kaltwasser, 2012, p. 17). This ambivalence is reflected in attitudes and participatory behavior of populist citizens (Zaslove et al., 2021). Populist citizens have been found to embrace "expressive non-institutionalized modes of participation" (Anduiza et al., 2019, p. 109) and hence are likely to express their views in user comments online. Galpin and Trenz (2019) introduced the term "participatory populism" for populist user comments that respond to online news and have pointed out negative consequences of this form of citizen engagement. This study follows this critical normative assessment, and suspects that populist user comments deteriorate the quality of online deliberation because their anti-pluralism, Manichaeism, and devaluation of expert knowledge constitute obstacles to civil, reciprocal, and informed online debates (Galpin \& Trenz, 2019, p. 784; Waisbord, 2018b).

Citizens and social media users have been repeatedly theorized as originators of populist messages (Engesser et al., 2017, p. 1284; Esser et al., 2017, p. 371; Krämer, 2017 , p. 1294). The bulk of empirical research on populist communication, however, has been focused on political elites (e.g., Ernst et al., 2019) or the media (e.g., Wettstein et al., 2018). Few studies have investigated populism in user comments empirically (Blassnig et al., 2019; Galpin \& Trenz, 2019). Galpin and Trenz (2019) focused on populist user comments on media websites during the 2019 European Parliamentary elections and found a clear anti-representative attitude in the user comments. Blassnig et al. (2019) analyzed comments reacting to news articles about immigration on media websites from three West European countries and found that populism in articles triggers populism in comments (Blassnig et al., 2019, p. 643). This article exceeds several limitations of these studies. First it broadens the sample size, given previous studies have analyzed only the first 10 to 20 comments per article (Blassnig et al., 2019, p. 636; Galpin \& Trenz, 2019, p. 797). Second, this study shifts the focus from news websites to comments on Facebook, which has proved to be highly popular among populist citizens (Schulz, 2019). Finally, the study asks a previously unasked question: How do news topics, and Covid-19 in particular, affect the scope of populist commenting?

\section{The Pandemic and Populist User Comments}

The pandemic has been accompanied by protests of "coronasceptics" and a proliferation of conspiracy myths online (Stephens, 2020). Scholars quickly linked these phenomena to populist ideology (Boberg et al., 2020; Brubaker, 2021; Eberl et al., 2021; Nachtwey et al., 2020). Following Brubaker (2021), these protests pick up anti-elitist and people-centric narratives because they challenge expert knowledge and juxtapose it with "common sense." Preliminary findings from a survey among German-speaking coronasceptics substantiated these claims (Nachtwey et al., 2020). Additionally, coronasceptics' calls to defy Covid measures can be under- stood as attempts to restore popular sovereignty. Yet, it is not self-evident that populists profited from this crisis as they did from previous crises (Buštíková \& Baboš, 2020, p. 505; Wondreys \& Mudde, 2020). In fact, at the beginning of the crisis, the Austrian and German population was highly supportive of the government measures (Kittel et al., 2021; Naumann et al., 2020).

Against this backdrop, populist political parties in Germany and Austria initially struggled to find a position on Covid crisis management. In Austria, the Freedom Party (Freiheitliche Partei Österreichs [FPÖ]), a "prototypical" populist radical right party that has been successful since the 1980s (Mudde \& Rovira Kaltwasser, 2013, p. 155), first pursued a discourse of "national unity" and supported the government measures, only to shift to a "coronasceptic" stance in April 2020 (Opratko, 2021). From then on, party representatives repeatedly questioned the credibility of public health experts and demonized the government measures as threats to freedom and democracy (Opratko, 2021). In Germany, the relatively young, populist radical right party Alternative for Germany (Alternative für Deutschland [AfD]; Fawzi et al., 2017) initially demanded even stricter measures to combat the pandemic (AfD, 2020), only to speak of a "Corona-Dictatorship" in a speech by Alexander Gauland (Deutscher Bundestag, 2020, p. 23358) in October 2020. The German left-wing populist party The Left (Die Linke), however, countered "coronasceptic" discourses (Die Linke, 2021). This study speculates that the shifts in the positions of populist (radical right) parties were in no small part driven by the emergence of a "coronasceptic," populist grassroots movement, which became increasingly vocal on social media. Instead of analyzing the consequences of such grassroots populism, the present study focuses on the conditions that shape populist grassroots engagement of ordinary citizens on social media. Specifically, this study aims to answer the question of how the news topic Covid-19, and aspects of the crisis management, have affected the scope of populist commenting on Facebook in Germany and Austria.

Drawing on psychological literature and public health communication research, this study expects that the topic Covid-19 strongly attracts populist comments. Facebook posts about Covid-19 arguably contain "fear appeals" (e.g., Witte, 1992). Fear appeals are, in a nutshell, "persuasive messages designed to scare people by describing the terrible things that will happen to them if they do not do what the message recommends" (Witte, 1992 , p. 329). Reports about a global pandemic do convey a frightening message. Moreover, such reports frequently include behavioral recommendations about how to avoid an infection. Though journalists may not be the initiators of such persuasive attempts, this article assumes that Facebook posts about Covid-19 frequently reiterate persuasive messages issued by government officials or public health experts. Following the "indexing" hypothesis, such reiteration is particularly likely in times of crisis (Bennett et al., 2007). 
Fear appeals, like any persuasive messages, can fail. One form of failure that is observed when the recommended behavior entails restrictions on personal freedoms is called "reactance" (Brehm \& Brehm, 1981; Dillard \& Shen, 2005). Reactance is "the motivational state that is hypothesized to occur when a freedom is eliminated or threatened" (Brehm \& Brehm, 1981, p. 37), which is arguably the case with restrictive Covid-19 measures. Though reactance is difficult to observe directly, it has been associated with rejective attitudes and behaviors, such as denying the existence of the threat, committing forbidden acts, or exercising a different freedom (Dillard \& Shen, 2005, p. 146). This article argues that populist user comments can be understood as a symptom of reactance. Populist comments undermine the credibility of the sender and the content of the message, for example by suggesting that the media is lying (Krämer, 2017, p. 1293). In the case of Covid, this questions the very existence of the threat (Brubaker, 2021, p 6). Furthermore, populist comments may call to reestablish lost freedoms by breaking Covid rules or may themselves constitute a compensatory behavior that provides a feeling of control (Dillard \& Shen, 2005, p. 146). This study argues that posts about Covid-19 trigger populist comments as a symptom of reactance:

H1: Posts about Covid-19 attract more populist comments than other posts.

Frequent repetitions of persuasive messages have been found to undermine persuasive attempts, decrease statement credibility, and trigger reactance (Koch \& Zerback, 2013). Ernst et al. (2017) showed that this is particularly the case for highly negative messages. Posts about Covid-19 address a highly negative topic and have been repeated frequently since the outbreak of the pandemic. In our data, $36 \%$ of all posts featured this topic. Following these considerations, this study expects that the effect hypothesized in $\mathrm{H} 1$ increases over time:

H2: The attraction of Covid-19 posts for populist comments grows over time.

Third, given reactance is understood as a reaction to impending restrictions to personal freedom (Brehm \& Brehm, 1981), this article expects a moderating effect of the stringency of Covid measures. Growing stringency of the measures implies greater restrictions on personal freedoms, and-if the reasoning here is correcta larger tendency to respond with reactance-related behavior. Understanding the connection between government measures and populist citizen engagement on social media also helps us fathom possibilities to counter populist online behavior politically.

H3: The attraction of Covid-19 posts for populist comments grows with the stringency of government measures.
Following a different line of thought, populist user comments can be understood as expressions of preexisting populist attitudes that are activated by a priming effect (Blassnig et al., 2019, p. 634). Priming, in communication research, refers to the effect that media content has on recipients' subsequent judgments and behavior (Roskos-Ewoldsen et al., 2002, p. 97). Priming activates specific concepts and cognitive schemata by increasing their accessibility in the recipient's memory (Blassnig et al., 2019, p. 634; Roskos-Ewoldsen et al., 2002). According to Krämer (2014, pp. 55-56), populist attitudes constitute such a schema that can be activated by specific message characteristics. This study argues that mentioning elite actors, especially government representatives and public health experts, may activate preexisting "populism schemata" (Krämer, 2014) and consequently increase the readiness of populist-minded users to express their views in user comments. Governmental representatives and public health experts have been the most visible actors in navigating the Covid-19 crisis (Brubaker, 2021, p. 2). Both actor groups are well established enemy images in populist communication and function as elitist scapegoats in populist blame attributions (Hameleers, 2018). This populist blame game should be particularly relevant in complex crisis situations because it creates a sense of security (Hameleers, 2018, p. 2180). Understanding how the visibility of public health experts affects populist citizen engagement online also helps us assess problems of crisis communication in the ongoing crisis. This lies in difficult terrain in which we face both an increased demand for expert knowledge and challenges from post-truth politics (Brubaker, 2021; Mede \& Schäfer, 2020; Waisbord, 2018a). This study expects that mentioning government representatives and experts amplifies the positive effect of the topic of Covid-19 on populist commenting:

H4a: The attraction of Covid-19 posts for populist comments grows with mentioning government representatives.

H4b: The attraction of Covid-19 posts for populist comments grows with mentioning experts.

\section{Methods}

To test these hypotheses, this study used data collected from the Facebook Graph API. Using digital trace data enhances external validity, compared to experimental designs, where populist expressions might be held back (Blassnig et al., 2019, p. 630). By selecting the cases of Germany and Austria, this study followed a most-likely research design (Levy, 2008, p. 12): If the hypothesized relations could not be found in these countries, where "coronasceptic" protests have taken on the proportions of a civic movement, they were unlikely to be found elsewhere. In Germany, the largest demonstrations of coronasceptics happened in summer 2020, and they gained 
traction in Austria in winter 2020-2021. Both countries are characterized by a similar political, historical, and economic background and faced similar challenges from the pandemic. Additionally, the common language allowed a consistent application of the content analysis tools.

\subsection{Data}

This study selected nine highly popular Facebook pages from media outlets, covering quality press (AT: Der Standard, Die Presse; DE: Der Spiegel, Die Zeit), tabloid press (AT: Kronen Zeitung, Ö24; DE: Bild), and public broadcasting news shows (AT: Zeit im Bild; DE: Tagesschau) in both countries. The selection followed a two-stage process. First, accounting for a hybrid media system (Chadwick, 2013), this study selected online news websites that are backed by traditional media brands and ranked them by their weekly reach in 2020 (Newman et al., 2020, pp. 63, 71). Then the corresponding Facebook pages were identified and ranked by the number of Facebook fans (on February 2020). The aim was to pick two Facebook pages per country for each category for quality press and tabloid press, and one page from a public broadcaster. For this study, Facebook pages that maximized the number of Facebook fans and the weekly reach of the associated website were selected. For Germany, this procedure resulted in preferring Facebook pages of weekly quality press (Der Spiegel, Die Zeit) over daily quality press because the former reached a larger online audience. Apart from Bild, there is no nationwide tabloid newspaper in Germany. For each Facebook page, the maximum number of publicly accessible Facebook posts, posted between 1 January 2020 and 30 May 2021, was downloaded from the Facebook API using Facepager (Jünger \& Keyling, 2020), resulting in $\mathrm{N}=25,121$ posts. For each Facebook post, up to 200 user comments were downloaded. This upper limit is considerably larger than the average number of Facebook comments per post, 134. In total, this study considered 1,443,273 Facebook user comments. The API returns user comments in anonymized form. Because the API returned data that were skewed toward recent posts, the study controlled for the posts' age at time of downloading.

\subsection{Dependent Variable}

The dependent variable here is the number of populist user comments per Facebook post, reflecting the scope of a collective populist voice in the Facebook comments section (Galpin \& Trenz, 2019, p. 782). To classify user comments as populist, this study applied an automated content analysis, employing Gründl's (2020) populism dictionary. Dictionary measurements count the occurrence of keywords in texts. Gründl's (2020) dictionary is tailored to social media content in the German language and covers all three conceptual dimensions of populism as defined earlier: anti-elitism, people-centrism, and popular sovereignty. Previous dictionary measurements of populist communication have been focused on anti-elitism alone (Rooduijn \& Pauwels, 2011), ignoring people-centric messages and demands for popular sovereignty. This study suspects that these two dimensions play a vital role in populist user comments, where "the people" arguably make themselves heard (Hameleers, 2018, p. 2179). In addition to this improved conceptual fit, Gründl's (2020) dictionary is technically superior to previous attempts because it covers a wide range of multiword expressions and outperformed other populism dictionaries in validity tests (Gründl, 2020, p. 13). In this study, a user comment was considered populist when at least one populist keyword was found. This accounts for the brevity of the comments ( 20 words avg.) and has been found sufficiently discriminating judged by face validity (see Appendix $C$ in the Supplementary File). Because automated content analyses raise questions of validity (Grimmer \& Stewart, 2013), this study validated all measurements thoroughly, as reported in the next section. The dependent variable is the aggregated count of populist Facebook comments per post.

\subsection{Explanatory Variables}

Three central explanatory variables are dichotomous indicators of a post's message characteristics: mentioning the topic of Covid-19, government figures, or experts. To measure these variables, this study developed, applied, and validated original dictionaries. Appendix A in the Supplementary File documents the dictionaries and their development. Additionally, this study captured whether a post mentioned the topics of party politics, economy, or border/migration, which might well have attracted populist comments (Betz, 1994; Burscher et al., 2015). This study tested validity of all dictionary measures against human coding of 450 posts and 450 comments. Both random samples were stratified to ensure sufficient coverage of the coded categories. Two coders, a student and the author, followed a codebook (see Appendix B in the Supplementary Flle) and reached satisfactory reliability scores when parallel-coding 80 posts and comments (see Table 1). Along with Krippendorff's alpha for reliability, Table 1 reports the validity scores precision, recall, and $F 1$. Recall indicates how well a dictionary captures all relevant documents, precision how well it captures only relevant documents, and $F 1$ is a harmonic mean of both. All measurements reached satisfactory scores, especially when compared to dictionaries in other tasks (Atteveldt et al., 2021, p. 128).

To operationalize time, this study computed the difference in days between the date of the post and the date when the WHO declared a global pandemic (March 11, 2020). Stringency of Covid-19 measures was operationalized as the stringency index coded by the Oxford Covid-19 Government Response Tracker (Hale et al., 2020). 
Table 1. Reliability and validity test.

\begin{tabular}{llccc}
\hline Concept & Krippendorff's $\alpha$ & Recall & Precision & F1 \\
\hline Populism $^{1}$ & $0.81(n=80)$ & 0.79 & 0.72 & 0.75 \\
Covid $^{2}$ & $0.97(n=80)$ & 0.91 & 0.96 & 0.93 \\
Government $^{2}$ & $0.90(n=80)$ & 0.86 & 0.80 & 0.83 \\
Experts $^{2}$ & $0.76(n=80)$ & 0.84 & 0.74 & 0.79 \\
Party politics $^{2}$ & $0.69(n=80)$ & 0.77 & 0.85 & 0.81 \\
Economy $^{2}$ & $0.80(n=80)$ & 0.70 & 0.77 & 0.73 \\
Border/Migration $^{2}$ & $0.92(n=80)$ & 0.71 & 0.85 & 0.77 \\
\hline
\end{tabular}

Notes: ${ }^{1}$ in comments, ${ }^{2}$ in posts.

\subsection{Control Variables}

In addition to controlling for other topics and the download age as mentioned previously, this study controlled for the severity of the crisis, using the rolling 7-day mean of daily new infections per 100,000 inhabitants of each country, based on data included in the Oxford Tracker (Hale et al., 2020). To model the number of times a populist comment could have been observed, all models included the logged number of downloaded comments per post plus 0.1 as an offset (Hilbe, 2011, p. 134). All con- tinuous independent variables but the offset were standardized and centered on population mean, while stringency and new cases were centered to their country mean. Table 2 reports summary statistics of all variables prior to transformation.

\subsection{Model Specification}

Because the dependent variable was a count variable and overdispersed, this study used negative binomial regression models to test the hypotheses (Hilbe, 2011).

Table 2. Summary statistics.

\begin{tabular}{|c|c|c|c|c|}
\hline Variables & Min. & Max. & Mean/n & $(\mathrm{SD}) /(\%)$ \\
\hline \multicolumn{5}{|l|}{ Dependent variable } \\
\hline Populist comments per post (count) & 0 & 165 & 1.5 & (3.3) \\
\hline \multicolumn{5}{|l|}{ Explanatory variables } \\
\hline Covid & 0 & 1 & 8,924 & $(36 \%)$ \\
\hline Government & 0 & 1 & 3,522 & $(14 \%)$ \\
\hline Experts & 0 & 1 & 1,717 & $(6.8 \%)$ \\
\hline Day count to/since March $11,2020^{2}$ & -70 & 445 & 257.4 & $(143.1)$ \\
\hline Stringency of government measures ${ }^{3}$ & 0 & 85.2 & 64.1 & (20.1) \\
\hline \multicolumn{5}{|l|}{ Controls } \\
\hline Economy & 0 & 1 & 2,628 & $(10 \%)$ \\
\hline Borders/migration & 0 & 1 & 904 & $(3.6 \%)$ \\
\hline Party politics & 0 & 1 & 1,869 & $(7.4 \%)$ \\
\hline New Covid-19 cases per 100k inhabitants ${ }^{3}$ & 0 & 83.6 & 17.3 & $(19.2)$ \\
\hline Download age ${ }^{2}$ & 0 & 395 & 75.2 & (74.9) \\
\hline \multicolumn{5}{|l|}{ Facebook accounts (grouping variable) } \\
\hline DER SPIEGEL (DE) & 0 & 1 & 2,253 & $(9.0 \%)$ \\
\hline DIE ZEIT (DE) & 0 & 1 & 2,243 & $(8.9 \%)$ \\
\hline Bild (DE) & 0 & 1 & 2,243 & $(8.9 \%)$ \\
\hline tagesschau (DE) & 0 & 1 & 2,216 & $(8.8 \%)$ \\
\hline Kronen Zeitung (AT) & 0 & 1 & 4,514 & $(18 \%)$ \\
\hline oe24.at (AT) & 0 & 1 & 4,045 & $(16 \%)$ \\
\hline DER STANDARD (AT) & 0 & 1 & 3,054 & $(12 \%)$ \\
\hline Die Presse (AT) & 0 & 1 & 3,739 & $(15 \%)$ \\
\hline Zeit im Bild (AT) & 0 & 1 & 814 & $(3.2 \%)$ \\
\hline \multicolumn{5}{|l|}{ Offset } \\
\hline Downloaded comments per post & 0 & 200 & 57.3 & $(70.7)$ \\
\hline Total comments per post ${ }^{1}$ & 0 & 13,257 & 134.4 & (389.5) \\
\hline Total (N posts) & & & 25,121 & \\
\hline
\end{tabular}

Notes: ${ }^{1}$ not in model, ${ }^{2}$ z-standardized, ${ }^{3}$ standardized and centered at country mean. 
To account for the clustering of the data on Facebook page level, this study ran fixed-effect models, which cancel out effects between accounts and focus on the effects on post level (Bell \& Jones, 2015, p. 139). Random-effects models confirmed the robustness of the findings, as documented in Appendix D in the Supplementary File.

\section{Results}

The descriptive statistics reported in Table 2 show that populist comments were a rather rare event in our data, with a mean of 1.5 populist comments per post. The results of the negative binomial regression models illuminate the factors that influenced the frequency of populist comments (see Table 3). Model 1 includes all basic variables, while model 2 adds the interaction terms. Hypothesis 1 posited that posts about Covid-19 would attract more populist comments than other posts, which is supported by the positive, significant coefficient for "Covid" in both models. Because the coeffi- cients are not directly interpretable, this study computed average marginal effects (AME). These tell us that mentioning Covid increased the predicted count of populist comments by .14 , holding all other variables at their observed values and then averaging across predictions for the whole sample. The only message characteristics that reached larger AMEs were mentioning the government (.28) and political parties (.71).

Hypothesis 2 posited that the effect of the topic of Covid would grow over time. This is supported by the significant, positive interaction term "Covid*Day count." The plot on the left in Figure 1 visualizes this effect, plotting the average predicted count of populist comments, conditional on "Covid" and "Day count." The standardized day count variable on the $x$-axis has a mean of zero, which corresponds to November 23, 2020, while one unit (SD) change represents 143 days. The solid line indicates the average predicted count for posts that mentioned the topic of Covid-19, while the dotted line relates to posts that did not. The distance between both lines on

Table 3. Results of negative binomial regression models.

Dependent Variable:

Populist comments per post (count)

(1)

(2)

\begin{tabular}{|c|c|c|}
\hline \multicolumn{3}{|l|}{ Explanatory variables } \\
\hline Covid & $0.09(0.02)^{* * *}$ & $0.10(0.02)^{* * *}$ \\
\hline Government & $0.17(0.02)^{* * *}$ & $0.28(0.03)^{* * *}$ \\
\hline Experts & $-0.05(0.03)$ & $-0.18(0.07)^{* *}$ \\
\hline Day count & $0.25(0.01)^{* * *}$ & $0.20(0.02)^{* * *}$ \\
\hline Stringency & $-0.05(0.01)^{* * *}$ & $-0.06(0.02)^{* * *}$ \\
\hline \multicolumn{3}{|l|}{ Interaction terms } \\
\hline Covid*Government & & $-0.20(0.04)^{* * *}$ \\
\hline Covid*Experts & & $0.15(0.08)$ \\
\hline Covid*Day Count & & $0.10(0.02)^{* * *}$ \\
\hline Covid*Stringency & & $0.08(0.02)^{* * *}$ \\
\hline \multicolumn{3}{|l|}{ Controls } \\
\hline New Covid-19 cases & $0.01(0.01)$ & $0.00(0.01)$ \\
\hline Download age & $-0.06(0.01)^{* * *}$ & $-0.06(0.01)^{* * *}$ \\
\hline Economy & $0.03(0.03)$ & $0.04(0.03)$ \\
\hline Borders/Migration & $0.11(0.04)^{* *}$ & $0.08(0.04)^{*}$ \\
\hline Party politics & $0.43(0.03)^{* * *}$ & $0.42(0.03)^{* * *}$ \\
\hline \multicolumn{3}{|l|}{ Accounts } \\
\hline DER SPIEGEL (GER) & $-0.13(0.03)^{* * *}$ & $-0.13(0.03)^{* * *}$ \\
\hline DIE ZEIT (GER) & $0.11(0.04)^{* *}$ & $0.11(0.04)^{* *}$ \\
\hline Bild (GER) & $-0.58(0.03)^{* * *}$ & $-0.56(0.03)^{* * *}$ \\
\hline Der Standard (AT) & $-0.28(0.05)^{* * *}$ & $-0.30(0.05)^{* * *}$ \\
\hline Die Presse (AT) & $-0.07(0.04)$ & $-0.08(0.04)^{*}$ \\
\hline Kronen Zeitung (AT) & $-0.46(0.03)^{* * *}$ & $-0.48(0.03)^{* * *}$ \\
\hline oe24.at (AT) & $-0.25(0.03)^{* * *}$ & $-0.26(0.03) * * *$ \\
\hline Zeit im Bild (AT) & $-0.11(0.04)^{* *}$ & $-0.11(0.04)^{* *}$ \\
\hline Observations & 25,121 & 25,121 \\
\hline Akaike information criterion (AIC) & $57,068.08$ & $56,975.54$ \\
\hline Bayesian information criterion (BIC) & $57,230.71$ & $57,170.69$ \\
\hline
\end{tabular}

Notes: ${ }^{* *} p<0.001 ;{ }^{* *} p<0.01 ;{ }^{*} p<0.05$; Offset: Downloaded comments $(\mathrm{n}+0.1$, logged). 

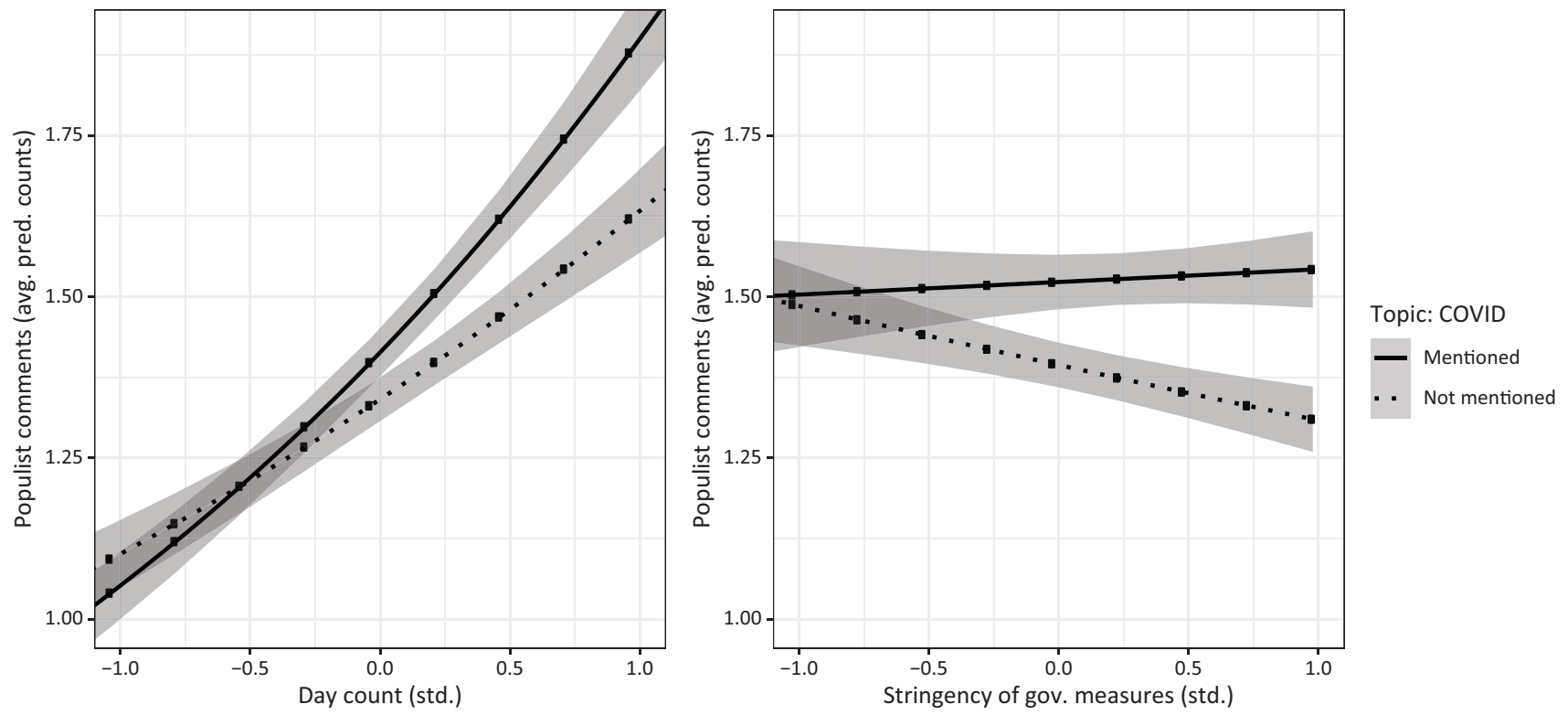

Figure 1. Interaction effects of Covid with time and with stringency (avg. pred. counts, 95\% confidence intervals).

the y-axis indicates the AME of "Covid," conditional to time, with the gray area indicating the $95 \%$ confidence interval. The plot shows that the AME of "Covid" grew from a negative effect in summer 2020 to .27 in mid-April 2021 , moving from -1 to +1 on the $x$-axis. The slope of the dotted line, however, indicates that the number of populist comments grew over time for other posts as well, an effect that is difficult to interpret.

Hypothesis 3 suggested an analogous interaction effect of the topic of Covid and measure stringency. Surprisingly, the overall effect of stringency was negative. With Covid measures getting stricter, fewer populist comments were observed overall. This negative relationship was driven particularly by posts that did not mention Covid-19, as indicated by the dotted line in the plot on the right side of Figure 1 . Surprisingly, this relation was not reversed but muted for posts that mentioned "Covid," as indicated by the low slope of the solid line. Although the conditional effect of government stringency for posts that mentioned Covid-19 was tendentially positive, increasing the average predicted count of populist comments by .04 when moving from -1 SD to $+1 \mathrm{SD}$, this effect did not surpass the $5 \%$ significance threshold. Based on these findings, this study discarded hypothesis 3 and discusses implications in the concluding section.

Hypotheses $4 \mathrm{a}$ and $4 \mathrm{~b}$ posited an amplification of the effect of Covid posts by mentioning the government and experts. Mentioning the government had an independent, positive effect on the number of populist comments. Surprisingly, mentioning experts did not and even had a negative effect in model 2 . The expected interaction effects ( $\mathrm{H} 4 \mathrm{a}$ and $\mathrm{H} 4 \mathrm{~b}$ ) were not confirmed by the models. Instead, model 2 estimated a significant, negative coefficient for "Covid*Government." In this case, the negative sign indicates that the positive effect of
"Government" shrank when Covid was mentioned but not that Covid posts attracted fewer populist comments if they mentioned the government.

The control variables indicate that the topics of migration and political parties attracted populist comments and that the download age affected the outcome. The dummy variables for the Facebook pages, which account for clustering of the data, suggest that the page of the baseline category, tagesschau, was only surpassed by Die Zeit in attracting populist comments. The concluding section interprets the findings substantially.

\section{Conclusions}

This article set out to study a problematic form of citizen engagement in the context of the Covid-19 crisis: populist commenting on news reports on Facebook. The study focused on Germany and Austria, where protests by "coronasceptics" grew into a civic movement that exhibited an affinity toward populist ideology (Nachtwey et al., 2020). Using a dataset of $\mathrm{N}=25,121$ Facebook posts and 1.4 million comments, posted between January 2020 and May 2021, and a validated, dictionary-based content analysis, this study analyzed how the topic of Covid-19 has attracted populist user comments on nine Facebook pages of German and Austrian mass media outlets.

The findings show that the topic Covid-19 has attracted more populist user comments than other posts and that this effect has grown over time. Apparently, the Facebook audience became increasingly annoyed by this topic and expressed this discontent by writing a growing number of populist comments. This article suggested interpreting these comments as expressions of "reactance" (Dillard \& Shen, 2005) and as a consequence of failed "fear appeals" (Witte, 1992) that are 
arguably contained in posts about Covid-19. The growing effect of Covid posts over time supports this interpretation because previous studies have shown that repeating appeals increases reactance (Koch \& Zerback, 2013). This finding confirms the well-established argument that crisis situations provide favorable conditions for populism (Hameleers, 2018, p. 2180), at least for the grassrootslike, populist citizen engagement on social media analyzed here. However, the finding that this effect only unfolded over time and the discussed initial struggles of populist political parties to find a coherent stance toward the crisis management indicate that this relationship might be more complex than in previous crises (Brubaker, 2021; Wondreys \& Mudde, 2020). Future research should explore the interplay between populist citizen engagement online and the positioning of populist parties in the context of the Covid-19 crisis further.

This study analyzed additional conditions under which citizens engage in populist commenting on social media. Surprisingly, the analysis did not find that the stringency of government measures triggered populist user comments or amplified the effect of the topic of Covid-19. An ad hoc explanation of this finding is that subjectively perceived restrictions of freedom might be more relevant for "coronasceptic" populists than objective restrictions (similarly, see Nachtwey et al., 2020, p. 60). This result also has implications for policy makers. Based on this finding, one cannot hope that relaxing the Covid-19 measures would considerably appease populists online. Decision makers may also be relieved that this study did not find that mentioning government representatives or public health experts amplified the attractiveness of Covid posts for populist comments. However, this study did find independent, positive effects for mentioning the government and political parties. Inspecting the content of the populist comments more thoroughly shows that mass media became a main target of populist attacks and was frequently decried as conformist propaganda (see Appendix C in the Supplementary File). Unfortunately, this finding takes its place in a growing list of worrisome developments in the online public sphere (e.g., Coe et al., 2014; Pfetsch, 2018). If social media users increasingly defame mass media reports as outright lies, the very basis for debates in the comments section gets lost. Although this development might be countered by moderating practices, more research on such counterstrategies is needed.

This study was not without limitations. Owing to its primary focus on populism and Covid, this study did not measure "reactance" and "fear appeals" directly and provided only circumstantial evidence for the psychological explanation suggested here. Appendices $A$ and $D$ in the Supplementary File report an attempt to measure fear appeals, which was discarded because it did not fully meet validity requirements. Future research is encouraged to test the psychological arguments presented in this study more directly in experimental designs. Further limitations stem from the applied automated content analysis. Although the dictionary approach used here enabled an efficient analysis of a large corpus of text and performed well in the validity tests, the depth of the resulting insights is limited. For example, it would be desirable to learn more about the actors who are attacked in populist comments; about related concepts, such as the spread of misinformation; or about comments that are critical toward the Covid measures but not necessarily populist. Future research may approach these questions using a nuanced, manual coding scheme. The study is also limited by its country selection. Extending this research to a comparative study of other European countries might provide more robust findings about the relationship between Covid-19 government measures and populist commenting.

Finally, contributing to a broader theme of this thematic issue, I want to address challenges for academic research that arise from working with the Facebook API. Accessing the Facebook API has become more and more difficult for researchers in the past few years. Many social media scholars today are dependent on endeavors like Facepager (Jünger \& Keyling, 2020). Such programs, however, have a precarious status themselves and constantly run the risk of losing the access granted by Facebook. A different problem is the lack of transparency and constant changes of the Facebook API. The data returned sometimes exhibit gaps or skewness for unclear reasons. This study included a download age control variable in the models to account for such biases. Recently, the Facebook API discontinued returning comment IDs, which renders the analysis of interactive user comments difficult. The anonymization of the comments is welcome for privacy reasons but certainly poses challenges for testing sociological and psychological explanations. The research community should clearly provide more institutional support for critical infrastructure such as Facepager in the medium term and establish free and reliable access to social media APIs in the long term.

\section{Acknowledgments}

I would like to thank the editors of this thematic issue, as well as Birgit Sauer, Christian Rauh, Benjamin Schürmann, Julia Partheymüller, and the two anonymous reviewers for their helpful feedback. Special thanks go to Anna Bil-Jaruzelska for inviting me to the workshop that preceded this issue. Proofreading was funded by the Vienna Doctoral School of Social Sciences. Open access funding was provided by University of Vienna.

\section{Conflict of Interests}

The author declares no conflict of interests.

\section{Supplementary Material}

Supplementary material for this article is available online in the format provided by the author (unedited). 


\section{References}

Alternative für Deutschland. (2020, March 12). Alice Weidel: COVID19-Nichtstun der Bundesregierung gefährdet Leib und Leben der Menschen [Alice Weidel: Covid-19-The federal government's inaction endangers the people's lives and limb]. Alternative für Deutschland. https://www.afd.de/aliceweidel-covid19-nichtstun-der-bundesregierunggefaehrdet-leib-und-leben-der-menschen

Anduiza, E., Guinjoan, M., \& Rico, G. (2019). Populism, participation, and political equality. European Political Science Review, 11(1), 109-124. https://doi.org/ 10.1017/S1755773918000243

Atteveldt, W. van, Velden, M. A. C. G. van der, \& Boukes, M. (2021). The validity of sentiment analysis: Comparing manual annotation, crowd-coding, dictionary approaches, and machine learning algorithms. Communication Methods and Measures, 15(2), 121-140. https://doi.org/10.1080/19312458.2020.1869198

Bell, A., \& Jones, K. (2015). Explaining fixed effects: Random effects modeling of time-series cross-sectional and panel data. Political Science Research and Methods, 3(1), 133-153. https://doi.org/10.1017/psrm. 2014.7

Bennett, W. L., Lawrence, R. G., \& Livingston, S. (2007). When the press fails: Political power and the news media from Iraq to Katrina. University of Chicago Press.

Betz, H.-G. (1994). Radical right-wing populism in Western Europe. The Macmillan Press.

Blassnig, S., Engesser, S., Ernst, N., \& Esser, F. (2019). Hitting a nerve: Populist news articles lead to more frequent and more populist reader comments. Political Communication, 36(4), 629-651. https://doi.org/ 10.1080/10584609.2019.1637980

Blassnig, S., \& Wirz, D. S. (2019). Populist and popular: An experiment on the drivers of user reactions to populist posts on Facebook. Social Media + Society, 5(4), 1-12. https://doi.org/10.1177/2056305119890062

Boberg, S., Quandt, T., Schatto-Eckrodt, T., \& Frischlich, L. (2020). Pandemic populism: Facebook pages of alternative news media and the Corona crisis-A computational content analysis. ArXiv. http://arxiv.org/abs/ 2004.02566

Brehm, S. S., \& Brehm, J. W. (1981). Psychological reactance: A theory of freedom and control. Academic Press.

Brubaker, R. (2021). Paradoxes of populism during the pandemic. Thesis Eleven, 164(1), 73-87. https://doi. org/10.1177/0725513620970804

Burscher, B., van Spanje, J., \& de Vreese, C. H. (2015). Owning the issues of crime and immigration: The relation between immigration and crime news and anti-immigrant voting in 11 countries. Electoral Studies, 38, 59-69. https://doi.org/10.1016/j.electstud. 2015.03.001

Buštíková, L., \& Baboš, P. (2020). Best in Covid: Pop- ulists in the time of pandemic. Politics and Governance, 8(4), 496-508. https://doi.org/10.17645/pag. v8i4.3424

Canovan, M. (1999). Trust the people! Populism and the two faces of democracy. Political Studies, 47(1), 2-16. https://doi.org/10.1111/1467-9248.00184

Chadwick, A. (2013). The hybrid media system: Politics and power. Oxford University Press. https://doi.org/ 10.1093/acprof:oso/9780199759477.001.0001

Coe, K., Kenski, K., \& Rains, S. A. (2014). Online and uncivil? Patterns and determinants of incivility in newspaper website comments. Journal of Communication, 64(4), 658-679. https://doi.org/10.1111/ jcom. 12104

Dahlberg, L. (2011). Re-constructing digital democracy: An outline of four "positions." New Media \& Society, 13(6), 855-872. https://doi.org/10.1177/ 1461444810389569

de Vreese, C. H., Esser, F., Aalberg, T., Reinemann, C., \& Stanyer, J. (2018). Populism as an expression of political communication content and style: A new perspective. The International Journal of Press/Politics, 23(4), 423-438. https://doi.org/10.1177/19401612 18790035

Deutscher Bundestag. (2020). Plenarprotokoll 19/186 [Plenary protocol 19/186]. https://dserver. bundestag.de/btp/19/19186.pdf

Die Linke. (2021). Corona, Exitdebatte und Verschwörungstheorien [Corona, exit debate, and conspiracy theories]. https://www.die-linke.de/ themen/gesundheit-und-pflege-alt/corona/faq

Dillard, J. P., \& Shen, L. (2005). On the nature of reactance and its role in persuasive health communication. Communication Monographs, 72(2), 144-168. https://doi.org/10.1080/03637750500111815

Eberl, J.-M., Huber, R. A., \& Greussing, E. (2021). From populism to the "plandemic": Why populists believe in Covid-19 conspiracies. Journal of Elections, Public Opinion and Parties, 31(Suppl. 1), 272-284. https:// doi.org/10.1080/17457289.2021.1924730

Engesser, S., Fawzi, N., \& Larsson, A. O. (2017). Populist online communication: Introduction to the special issue. Information, Communication \& Society, 20(9), 1279-1292. https://doi.org/10.1080/ 1369118X.2017.1328525

Ernst, N., Blassnig, S., Engesser, S., Büchel, F., \& Esser, F. (2019). Populists prefer social media over talk shows: An analysis of populist messages and stylistic elements across six countries. Social Media + Society, 5(1), 1-14. https://doi.org/10.1177/ 2056305118823358

Ernst, N., Kühne, R., \& Wirth, W. (2017). Effects of message repetition and negativity on credibility judgments and political attitudes. International Journal of Communication, 11, 3265-3285.

Esser, F., Stępińska, A., \& Hopmann, D. N. (2017). Populism and the media: Cross-national findings and perspectives. In T. Aalberg, F. Esser, C. Reinemann, 
J. Stromback, \& C. H. de Vreese (Eds.), Populist political communication in Europe (pp. 365-380). Routledge.

Fawzi, N., Obermaier, M., \& Reinemann, C. (2017). Germany: Is the populism laggard catching up? In T. Aalberg, F. Esser, C. Reinemann, J. Strömbäck, \& C. H. de Vreese (Eds.), Populist political communication in Europe (pp. 111-126). Routledge.

Friess, D., \& Eilders, C. (2015). A systematic review of online deliberation research. Policy \& Internet, 7(3), 319-339. https://doi.org/10.1002/poi3.95

Galpin, C., \& Trenz, H.-J. (2019). Participatory populism: Online discussion forums on mainstream news sites during the 2014 European Parliament election. Journalism Practice, 13(7), 781-798. https://doi.org/ 10.1080/17512786.2019.1577164

Grimmer, J., \& Stewart, B. M. (2013). Text as data: The promise and pitfalls of automatic content analysis methods for political texts. Political Analysis, 21(3), 267-297. https://doi.org/10.1093/pan/mps028

Gründl, J. (2020). Populist ideas on social media: A dictionary-based measurement of populist communication. New Media \& Society. Advance online publication. https://doi.org/10.1177/1461444820976970

Hale, T., Angrist, N., Cameron-Blake, E., Hallas, L., Kira, B., Majumdar, S., Petherick, A., Phillips, T., \& Tatlow, H. (2020). Oxford Covid-19 government response tracker. Blavatnik School of Government. https://www.bsg.ox.ac.uk/research/researchprojects/coronavirus-government-response-tracker Hameleers, M. (2018). A typology of populism: Toward a revised theoretical framework on the sender side and receiver side of communication. International Journal of Communication, 12, 2171-2190.

Hilbe, J. M. (2011). Negative binomial regression (2nd ed.). Cambridge University Press. https://doi. org/10.1017/CBO9780511973420

Jamieson, K. H., \& Cappella, J. N. (2008). Echo chamber: Rush Limbaugh and the conservative media establishment. Oxford University Press.

Jünger, J., \& Keyling, T. (2020). Facepager. An application for automated data retrieval on the web (4.2) [Computer software]. https://github.com/strohne/ Facepager

Kittel, B., Kritzinger, S., Boomgaarden, H., Prainsack, B., Eberl, J.-M., Kalleitner, F., Lebernegg, N. S., Partheymüller, J., Plescia, C., Schiestl, D. W., \& Schlogl, L. (2021). The Austrian Corona Panel Project: Monitoring individual and societal dynamics amidst the Covid-19 crisis. European Political Science, 20(2), 318-344. https://doi.org/10.1057/s41304020-00294-7

Klinger, U., \& Svensson, J. (2015). The emergence of network media logic in political communication: A theoretical approach. New Media \& Society, 17(8), 1241-1257. https://doi.org/10.1177/14614448145 22952

Knoll, J., Matthes, J., \& Heiss, R. (2018). The social media political participation model: A goal systems theory perspective. Convergence, 26(1), 135-156. https:// doi.org/10.1177/1354856517750366

Koch, T., \& Zerback, T. (2013). Helpful or harmful? How frequent repetition affects perceived statement credibility. Journal of Communication, 63(6), 993-1010. https://doi.org/10.1111/jcom.12063

Krämer, B. (2014). Media populism: A conceptual clarification and some theses on its effects. Communication Theory, 24(1), 42-60. https://doi.org/10.1111/ comt.12029

Krämer, B. (2017). Populist online practices: The function of the Internet in right-wing populism. Information, Communication \& Society, 20(9), 1293-1309. https://doi.org/10.1080/1369118X.2017.1328520

Levy, J. S. (2008). Case studies: Types, designs, and logics of inference. Conflict Management and Peace Science, 25(1), 1-18. https://doi.org/10.1080/ 07388940701860318

Macafee, T. (2013). Some of these things are not like the others: Examining motivations and political predispositions among political Facebook activity. Computers in Human Behavior, 29(6), 2766-2775. https:// doi.org/10.1016/j.chb.2013.07.019

Mede, N. G., \& Schäfer, M. S. (2020). Science-related populism: Conceptualizing populist demands toward science. Public Understanding of Science, 29(5), 473-491. https://doi.org/10.1177/0963662520924 259

Mudde, C. (2004). The populist zeitgeist. Government and Opposition, 39(4), 541-563. https://doi.org/ 10.1111/j.1477-7053.2004.00135.x

Mudde, C., \& Kaltwasser, C. R. (2012). Populism and (liberal) democracy: A framework for analysis. In C. Mudde \& C. Rovira Kaltwasser (Eds.), Populism in Europe and the Americas: Threat or corrective for democracy? (pp. 1-26). Cambridge University Press.

Mudde, C., \& Rovira Kaltwasser, C. (2013). Exclusionary vs. inclusionary populism: Comparing contemporary Europe and Latin America. Government and Opposition, 48(2), 147-174. https://doi.org/10.1017/gov. 2012.11

Nachtwey, O., Schäfer, R., \& Frei, N. (2020). Politische Soziologie der Corona-Proteste [Political sociology of the Corona-protests]. SocArXiv. https://doi.org/ 10.31235/osf.io/zyp3f

Naumann, E., Möhring, K., Reifenscheid, M., Wenz, A., Rettig, T., Lehrer, R., Krieger, U., Juhl, S., Friedel, S., Fikel, M., Cornesse, C., \& Blom, A. G. (2020). Covid-19 policies in Germany and their social, political, and psychological consequences. European Policy Analysis, 6(2), 191-202. https://doi.org/10.1002/ epa2.1091

Newman, N., Fletcher, R., Schulz, A., Andı, S., \& Nielsen, R. K. (2020). Reuters Institute digital news report 2020. Reuters Institute for the Study of Journalism. https://reutersinstitute.politics.ox.ac.uk/sites/ default/files/2020-06/DNR_2020_FINAL.pdf 
Opratko, B. (2021, September 8-10). From "national unity" to "stop the madness." Authoritarian populism and the Covid crisis: The case of the Austrian Freedom Party [Paper presentation]. Joint conference of the DVPW Populism Group and the PSA Populism Specialist Group, Berlin, Germany.

Pfetsch, B. (2018). Dissonant and disconnected public spheres as challenge for political communication research. Javnost-The Public, 25(1/2), 59-65. https://doi.org/10.1080/13183222.2018.1423942

Pressman, J., \& Choi-Fitzpatrick, A. (2021). Covid19 and protest repertoires in the United States: An initial description of limited change. Social Movement Studies, 20(6), 766-773. https://doi.org/ 10.1080/14742837.2020.1860743

Rooduijn, M., Brug, W. van der, Lange, S. L. de, \& Parlevliet, J. (2017). Persuasive populism? Estimating the effect of populist messages on political cynicism. Politics and Governance, 5(4), 136-145. https://doi. org/10.17645/pag.v5i4.1124

Rooduijn, M., \& Pauwels, T. (2011). Measuring populism: Comparing two methods of content analysis. West European Politics, 34(6), 1272-1283. https://doi.org/ 10.1080/01402382.2011.616665

Roskos-Ewoldsen, D. R., Roskos-Ewoldsen, B., \& Carpentier, F. R. D. (2002). Media priming: A synthesis. In J. Bryant \& D. Zillmann (Eds.), Media effects: Advances in theory and research (2nd ed., pp. 97-120). Lawrence Erlbaum Associates Publishers.

Rowe, I. (2015). Deliberation 2.0: Comparing the deliberative quality of online news user comments across platforms. Journal of Broadcasting \& Electronic Media, 59(4), 539-555. https://doi.org/10.1080/ 08838151.2015 .1093482

Schulz, A. (2019). Where populist citizens get the news: An investigation of news audience polarization along populist attitudes in 11 countries. Communication Monographs, 86(1), 88-111. https://doi.org/
10.1080/03637751.2018.1508876

Stephens, M. (2020). A geospatial infodemic: Mapping Twitter conspiracy theories of Covid-19. Dialogues in Human Geography, 10(2), 276-281. https://doi.org/ $10.1177 / 2043820620935683$

Waisbord, S. (2018a). The elective affinity between posttruth communication and populist politics. Communication Research and Practice, 4(1), 17-34. https:// doi.org/10.1080/22041451.2018.1428928

Waisbord, S. (2018b). Why populism is troubling for democratic communication. Communication, Culture and Critique, 11(1), 21-34. https://doi.org/10.1093/ $\mathrm{ccc} / \mathrm{tcx} 005$

Wettstein, M., Esser, F., Schulz, A., Wirz, D. S., \& Wirth, W. (2018). News media as gatekeepers, critics, and initiators of populist communication: How journalists in ten countries deal with the populist challenge. International Journal of Press/Politics, 23(4), 476-495. https://doi.org/10.1177/1940161218785979

Witte, K. (1992). Putting the fear back into fear appeals: The extended parallel process model. Communication Monographs, 59(4), 329-349. https://doi.org/ 10.1080/03637759209376276

Wondreys, J., \& Mudde, C. (2020). Victims of the pandemic? European far-right parties and Covid-19. Nationalities Papers. Advance online publication. https://doi.org/10.1017/nps.2020.93

Zaslove, A., Geurkink, B., Jacobs, K., \& Akkerman, A. (2021). Power to the people? Populism, democracy, and political participation: A citizen's perspective. West European Politics, 44(4), 727-751. https://doi. org/10.1080/01402382.2020.1776490

Zerback, T., \& Fawzi, N. (2017). Can online exemplars trigger a spiral of silence? Examining the effects of exemplar opinions on perceptions of public opinion and speaking out. New Media \& Society, 19(7), 1034-1051. https://doi.org/10.1177/1461444 815625942

\section{About the Author}

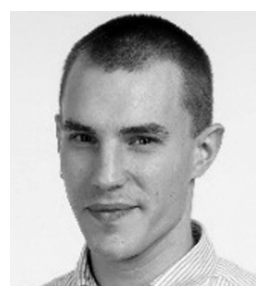

Daniel Thiele is a PhD candidate and research assistant at the Department of Political Sciences at the University of Vienna. His thesis focuses on emotional populist communication and citizen engagement on social media. His research interests include political communication, political participation, populism, emotions, and quantitative methods. 